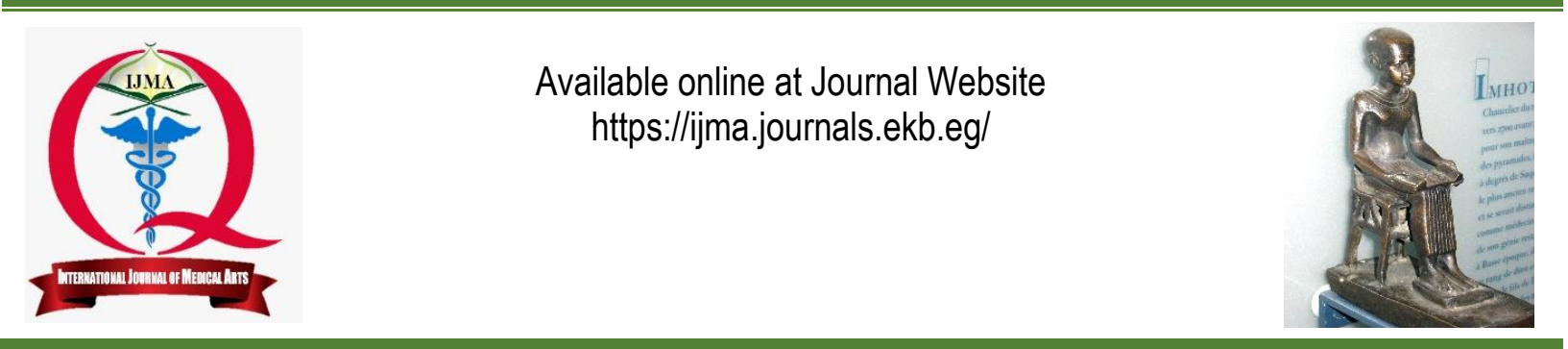

Original article

\title{
A comparative Study Between Pethidine, Granisetron and Tramadol in Prophylaxis Against Perioperative Shivering After Spinal Anesthesia
}

\author{
Yousry Abdelsalam \\ Department of Anesthesia and Intensive Care, Damietta Faculty of Medicine, Al-Azhar University, Egypt \\ Email: yousry.abdelsalam@domazhermedicine.edu.eg \\ Received at: November 16, 2019; Revised at: February 1, 2020; Accepted at: February 1, 2020; Available online at: February 1, 2020 \\ DOI: 10.21608/ijma.2020.19679.1044
}

\section{ABSTRACT}

Background: Peri-operative shivering, a challenging discomfort faced in anesthesiologists' daily practice. Many drugs were used as a prophylaxis, but there was no consensus on ideal or standard drug yet.

Aim of the work: To compare the effectiveness and safety of pethidine, granisetron and tramadol in prophylaxis against perioperative shivering after spinal anesthesia.

Patients and methods: Sixty adult patients, who underwent spinal anesthesia, were included. They were randomly assigned to granisetron, pethidine or tramadol (20 in each group), and submitted to standard intraoperative monitoring and follow up for postoperative 4 hours. Monitoring included electrocardiography, oxygen saturation, respiratory rate, temperature, non-invasive blood level, conscious level and sedation score. Side effects were documented.

Results: Intra- and post-operatively, there was significant reduction of heart rate in granisetron and tramadol groups. Mean arterial pressure significantly decreased in granisetron group at the time from 30 minutes to the end of surgery and during the first two postoperative hours. Respiratory rate significantly decreased in pethidine group during the complete intra- and post-operative period. Granisetron had no sedative effect at all, but sedation was significantly increased among pethidine group. Finally, perioperative shivering was reported in $25 \%, 15 \%$ and $15 \%$ of pethidine, granisetron and tramadol groups respectively. Nausea/vomiting was reported in $20 \%, 10.0 \%$, and $0 \%$ of pethidine, tramadol and granisetron groups respectively. Pruritus was confined to $30 \%$ pethidine group with significant difference.

Conclusion: Granisetron, tramadol and pethidine, all are effective as a prophylaxis against perioperative shivering after spinal anesthesia. However, granisetron seems to be the most suitable drug.

Keywords: Spinal anesthesia; Regional anesthesia; Tramadol; Pethidine; Granisetron.

This is an open access article under the Creative Commons license [CC BY] [https://creativecommons.org/licenses/by/2.0/]

Please cite this article as Abdelsalam Y. A comparative Study Between Pethidine, Granisetron and Tramadol in Prophylaxis Against Perioperative Shivering After Spinal Anesthesia. IJMA 2020; 2[1]: 292-300. 


\section{INTRODUCTION}

During perioperative period, shivering is one of the commonest challenges (the incidence ranges between 20 and $80.0 \%$ ). Different studies reported that, shivering increase oxygen consumption and $\mathrm{CO}_{2}$ production. It also affects monitoring and increase intraocular and intracranial pressure [1,2].

Perioperative shivering remains common irrespective of rigorous efforts to prevent perioperative hypothermia [3,4]. The main etiologies for intra/postoperative shivering are loss of temperature, reduced sympathetic tone and pyrogenic release [5]. In a previous trial, risk factors for developing perioperative shivering include but not limited to younger age, endoprosthetic surgery, long surgery duration and low core body temperature ${ }^{[6]}$.

Regional anesthesia is associated with vasodilatation, which facilitates core to peripheral redistribution of heat. It also led to increase in sweating threshold and reduction of vasoconstriction and shivering threshold [5]. Preventing or decreasing perioperative and specifically postoperative shivering can reduce risk of adverse events of perioperative shivering and can shorten the patient's stay duration in the post-anesthesia care unit (PACU) ${ }^{[4]}$.

There are pharmacological and non-pharmacological interventions to control perioperative shivering. Non-pharmacological maneuvers include fluid warmers, monitoring ambient temperature of operating theatre, space blankets, and surgical drapes. However, its effectiveness is questioned [7].

As pharmacological intervention could decrease the incidence of perioperative shivering, many drugs were tried. The list of drugs with antishivering effects include dexmedetomidine [8], 5hydroxytryptamine-3 receptor antagonists [9], meperidine [10], fentanyl, buprenorphine, doxapram, clonidine [11]. However, these drugs were not widely used due to its high cost and their safety is disputed[12].

\section{AIM OF THE WORK}

The present study was designed to compare the effectiveness and safety of pethidine, granisetron and tramadol in prophylaxis against perioperative shivering of patient undergoing spinal anesthesia.

\section{PATIENTS AND METHODS}

The present study was designed as a randomized comparative trial that included 60 adult patients, ASA physical status I or II, aged between 18-55 years, who scheduled for elective surgery in the lower limb and lower abdominal surgery as appendectomy, repair of inguinal hernia, endoscopic cystoscopy and knee or hip arthroplasty who was undergoing spinal anesthesia. There were selected from Al-Azhar University hospital (New Damietta). The study was carried out during the period from March 2017 to March 2019.

The study protocol was approved by a local research and ethics committee of Al-Azhar Faculty of Medicine (New Damietta); and each participant provided an informed consent after full clarification of the study was explained to each one and their rights for withdrawal at any time was assured and their privacy were guaranteed.

Exclusion criteria include patient refusal, pregnancy, surgical procedures required blood transfusion or transfusion of any of blood products, urologic endoscopic interventions, obese (BMI > 30 $\mathrm{kg} / \mathrm{m}^{2}$ ), patients with cardiopulmonary disease, thyroid disease and those with established allergy for any of studied drugs.

Eligible subjects were randomly divided into three equal groups (each included 20 subjects) according to the drug used as anti-shivering agent. Randomization was carried out by generating a series of numbers by a computer; each number preserved in an enclosed envelope that opened by a resident not involved in the study just before spinal anesthesia.

Patients of pethidine group $(n=20)$ received intravenous (IV) pethidine $0.4 \mathrm{mg} / \mathrm{kg}$ body weight. Granisetron group $(n=20)$ received IV granisetron (40 $\mu \mathrm{g} / \mathrm{kg}$ body weight). Tramadol group $(\mathrm{n}=20)$ received IV tramadol $1 \mathrm{mg} / \mathrm{kg}$ body weight five minutes before spinal anesthesia.

In the operating room, standard monitoring was used for all subjects and each patient was preloaded with $10 \mathrm{ml} / \mathrm{kg}$ of Ringer lactate over 15 minutes. Anesthetic equipment and drugs for resuscitation were kept ready at hand before starting the spinal anesthesia. All preloading fluids 
and the IV infusions used during operations were prewarmed to a temperature of approximately $37{ }^{\circ} \mathrm{C}$. Operation room temperature was kept at $22^{\circ} \mathrm{C} \pm 1^{\circ} \mathrm{C}$.

Under complete aseptic conditions, spinal anesthesia was performed in the level of L3-4 space, using a $25 \mathrm{G}$ sterile disposable Quincke's spinal needle by $0.5 \%$ hyperbaric bupivacaine $15 \mathrm{mg}$ at a rate of $0.2 \mathrm{ml} / \mathrm{sec}$. Standard monitoring included: electrocardiography, oxygen saturation, respiratory rate, temperature, non-invasive blood pressure, conscious level and sedation score. Side effects were documented.

The spinal block levels were assessed by pinprick at the midaxillary line, 5 minutes after spinal anesthesia. When the level of block reached T8-10 level, patients were ready for operation. Shivering was assessed in all patients and grading on a 5point scale.

Table [1]: The Five-item scale of assessing shivering [13]

- No shivering

- Piloerection, peripheral vasoconstriction or peripheral cyanosis without other cause

- Visible muscular activity confined to one muscle group

- Visible muscular activity in more than one muscle group

- Gross muscular activity involving the entire body

The level of sedation was evaluated by a 5 point numeric scale, where " $1=$ completely awake, 2=awake but drowsy, $3=a$ sleep but responsive to verbal commands, $4=$ asleep but responsive to tactile stimulus, 5=asleep and not responsive to any stimuli)"[14].

Perioperative nausea and/or vomiting were assessed using a four-point ordinal score where zero stands for no nausea/vomiting, one stands for nausea, two stands for retching, and three for vomiting. Intravenous metoclopramide $10 \mathrm{mg}$ was used as a rescue drug for nausea/vomiting.

Pruritus was assessed by a four-point ordinal scale to rate where zero points to no itching, one points to mild itching, two points to moderate itching, treatment not requested, three points to severe itching, treatment requested.

Fluid management intraoperatively was done according to body weight of the patient and intraoperative losses. All patients were given oxygen by Hudson's facemask at a rate of 5 litres/min. This monitoring continued even at the postoperative period for 4 hours. Temperature at recovery room was kept at $22-24^{\circ} \mathrm{C}$.

Adverse reactions like bradycardia ( $\mathrm{HR}<50$ bpm), hypotension (systolic blood pressure< $90 \mathrm{mmHg}$ or $<30 \%$ preoperative value), respiratory depression (respiratory rate $<8 / \mathrm{min}$ ), urinary retention was also documented throughout the post-operative period
Statistical data analysis: All the data collected were expressed as mean and standard deviation for quantitative continuous data, frequency and percentage for qualitative data and analyzed using Chi Square tests and Analysis of Variance (ANOVA) wherever applicable, $\mathrm{P}$ value of $<0.05$ was considered significant.

\section{RESULTS}

In the present work, patient age ranged from 33 to 50 years and $61.7 \%$ were males. Patient weight ranged from 62 to $84 \mathrm{~kg}$ and $63.3 \%$ of patients were ASA class I. Finally, the operative time ranged from 74 to 99 minutes; the mean value was $85.08 \pm 5.93$ minutes; and there was no significant difference between studied groups regard any of patient characters or operative time (Table 6).

Regarding heart rate, there was no significant difference between groups before operation (Basal measurement). Intraoperatively, there was significant decrease of heart rate in both granisetron and tramadol groups when compared to pethidine group. Postoperative, there is still significant decrease of HR in tramadol group when compared to granisetron group and when compared to pethidine group at the first two hours postoperatively. However, no brady or tachycardia were reported in studied patients at any time; and at the end of follow up period (4 hours postoperatively), the three groups returned near to the basal values (Table 3). 
Regarding mean arterial pressure, there was no significant difference between groups at basal values, at the first intraoperative (15 minutes) and at $3 \& 4$ hours postoperatively. However, there was statistically significant decrease of mean arterial blood pressure in granisetron group at the rest of intraoperative time (from 30 minutes to the final intraoperative measurement) and during the first two postoperative hours (Table 4). Respiratory rate showed non-significant difference between groups at basal values. However, there was significant decrease of respiratory rate in pethidine when compared to either granisetron or tramadol groups during the whole intraoperative and postoperative period (Table 5).

In the present work, there was no significant difference between studied groups as regard to mean oxygen saturation all skin temperature throughout the whole study duration (Table 6).

Regarding sedation score among studied groups, granisetron had no sedative effect at all. Otherwise, there was statistically significant increase of sedation score among pethidine when compared to tramadol from the 30 minutes intra operatively until the end of study duration (Table 7).

Regarding outcome, perioperative shivering was reported in $25 \%$ of patients in pethidine group and $15 \%$ in each of granisetron and tramadol groups; with no significant difference between groups. It was mild in $66.7 \%$ of granisetron group and $20 \%$ of pethidine group; and shivering was moderate in $33.3 \%$ of granisetron group, $80.0 \%$ of pethidine group and $100.0 \%$ of tramadol group. Nausea and/or vomiting was reported in $20 \%$ of pethidine group, $10.0 \%$ of tramadol group and none in granisetron group, with no significant difference between groups. Finally, pruritus was confined to pethidine group and reported in $30.0 \%$ of patients in such group, with significant difference between groups (Table 8).

Table (2): Comparison between groups as regard to patient characteristics and operative time (Mean \pm SD)

\begin{tabular}{|c|c|c|c|c|c|}
\hline & ariables & Granisetron & Pethidine & Tramadol & $P$ \\
\hline \multicolumn{2}{|c|}{ Age (mean $\pm S D ;$ min-max.) } & $41.55 \pm 3.59 ; 37-49$ & $40.75 \pm 4.27 ; 35-49$ & $39.35 \pm 5.49 ; 33-50$ & $0.30(\mathrm{~ns})$ \\
\hline \multirow[b]{2}{*}{ Sex } & Male & $11(55.0 \%)$ & $12(60.0 \%)$ & $14(70.0 \%)$ & \multirow[t]{2}{*}{0.61 (ns) } \\
\hline & \begin{tabular}{|l|} 
Female \\
\end{tabular} & $9(45.0 \%)$ & $8(40.0 \%)$ & $6(30.0 \%)$ & \\
\hline \multicolumn{2}{|c|}{ Weight (mean $\pm S D$; min-max.) } & $73.20 \pm 5.30 ; 62-80$ & $72.85 \pm 5.92 ; 63-82$ & $75.15 \pm 4.85 ; 64-84$ & \multirow{3}{*}{$\begin{array}{l}0.35(\mathrm{~ns}) \\
0.61(\mathrm{~ns})\end{array}$} \\
\hline \multirow[b]{2}{*}{ ASA } & I & $13(65.0 \%)$ & $14(70.0 \%)$ & $11(55.0 \%)$ & \\
\hline & $\|$ & $7(35.0 \%)$ & $6(30.0 \%)$ & $9(45.0 \%)$ & \\
\hline \multicolumn{2}{|c|}{ Operative time (min) } & $87.30 \pm 6.35 ; 78-98$ & $83.95 \pm 6.21 ; 74-99$ & $84.00 \pm 4.72 ; 76-94$ & $0.12(\mathrm{~ns})$ \\
\hline
\end{tabular}

ASA: American Society of Anesthesiology; ns: non-significant

Table (3): Comparison between groups as regard to peri-operative heart rate (beat/minute) (Mean \pm SD)

\begin{tabular}{|c|c|c|c|c|c|c|c|c|c|}
\hline \multicolumn{2}{|c|}{ Heart rate } & \multicolumn{2}{|c|}{ Granisetron } & \multicolumn{2}{|c|}{ Pethidine } & \multicolumn{2}{|c|}{ Tramadol } & \multirow[t]{2}{*}{$\mathrm{F}$} & \multirow[t]{2}{*}{$p$} \\
\hline & & Mean & SD & Mean & SD & Mean & SD & & \\
\hline \multicolumn{2}{|l|}{ Basal } & 80.30 & 2.83 & 80.75 & 2.83 & 81.70 & 3.03 & 1.22 & 0.303 \\
\hline \multirow{6}{*}{ Intraoperative } & 15 minutes & 78.45 & 2.46 & 89.10 & 2.47 & 77.45 & 2.19 & 147.74 & $<0.001^{*}$ \\
\hline & 30 minutes & 78.20 & 2.55 & 90.45 & 2.16 & 76.30 & 1.95 & 236.47 & $<0.001^{*}$ \\
\hline & 45 minutes & 77.95 & 2.06 & 90.95 & 1.99 & 75.80 & 1.67 & 366.32 & $<0.001^{*}$ \\
\hline & 60 minutes & 78.30 & 2.52 & 88.30 & 2.64 & 75.55 & 1.99 & 156.79 & $<0.001^{*}$ \\
\hline & 75 minutes & 77.95 & 2.82 & 85.80 & 3.19 & 75.70 & 1.89 & 77.73 & $<0.001^{*}$ \\
\hline & Final & 77.70 & 2.64 & 83.75 & 2.84 & 76.10 & 2.15 & 49.66 & $<0.001^{*}$ \\
\hline \multirow{6}{*}{ Postoperative } & 0 minute & 81.90 & 2.31 & 80.70 & 3.95 & 78.15 & 1.60 & 9.36 & $<0.001^{*}$ \\
\hline & 30 minutes & 81.60 & 2.30 & 80.85 & 3.54 & 78.50 & 1.76 & 7.49 & $0.001^{*}$ \\
\hline & 60 minutes & 81.45 & 1.85 & 80.05 & 3.59 & 78.80 & 1.51 & 5.67 & $0.006^{*}$ \\
\hline & Two hours & 81.35 & 1.81 & 79.95 & 3.66 & 78.90 & 1.37 & 4.88 & $0.011^{*}$ \\
\hline & Three hours & 81.40 & 1.67 & 79.75 & 3.31 & 79.40 & 1.35 & 4.40 & $0.017^{*}$ \\
\hline & Four hours & 81.35 & 1.76 & 79.10 & 3.78 & 80.10 & 1.45 & 3.91 & $0.026^{*}$ \\
\hline
\end{tabular}

*significant 
Abdelsalam Y.

Table (4): Comparison between groups as regard to perioperative mean arterial pressure ( $\mathrm{mmHg}$ )

\begin{tabular}{|c|c|c|c|c|c|c|c|c|c|}
\hline \multirow{2}{*}{\multicolumn{2}{|c|}{ Mean arterial pressure }} & \multicolumn{2}{|c|}{ Granisetron } & \multicolumn{2}{|c|}{ Pethidine } & \multicolumn{2}{|c|}{ Tramadol } & \multirow[t]{2}{*}{$F$} & \multirow[t]{2}{*}{$p$} \\
\hline & & Mean & SD & Mean & SD & Mean & SD & & \\
\hline \multicolumn{2}{|l|}{ Basal } & 101.10 & 3.45 & 99.85 & 2.46 & 100.65 & 3.30 & 0.84 & 0.439 \\
\hline \multirow{6}{*}{ Intraoperative } & 15 minutes & 87.80 & 3.52 & 88.35 & 1.79 & 89.25 & 2.45 & 1.49 & 0.234 \\
\hline & 30 minutes & 83.60 & 1.64 & 86.95 & 2.06 & 86.10 & 2.00 & 16.66 & $<0.001^{*}$ \\
\hline & 45 minutes & 82.85 & 1.53 & 85.15 & 2.11 & 85.85 & 1.53 & 16.17 & $<0.001^{*}$ \\
\hline & 60 minutes & 82.95 & 1.73 & 85.65 & 3.08 & 85.70 & 1.49 & 10.09 & $<0.001^{*}$ \\
\hline & 75 minutes & 83.45 & 1.85 & 87.85 & 2.87 & 86.50 & 1.40 & 22.41 & $<0.001^{*}$ \\
\hline & Final & 84.50 & 1.88 & 89.15 & 3.07 & 87.30 & 2.30 & 18.07 & $<0.001^{*}$ \\
\hline \multirow{6}{*}{ Postoperative } & 0 minute & 86.45 & 2.33 & 90.35 & 2.92 & 88.90 & 1.97 & 13.06 & $<0.001^{*}$ \\
\hline & 30 minutes & 87.05 & 2.09 & 90.70 & 3.11 & 89.50 & 1.91 & 11.74 & $<0.001^{*}$ \\
\hline & 60 minutes & 88.00 & 2.45 & 90.80 & 2.61 & 89.50 & 2.42 & 6.32 & $0.003^{*}$ \\
\hline & Two hours & 89.05 & 2.01 & 91.00 & 2.25 & 90.40 & 1.73 & 4.95 & $0.010^{*}$ \\
\hline & Three hours & 90.30 & 2.03 & 90.90 & 2.55 & 90.85 & 1.76 & 0.48 & 0.618 \\
\hline & Four hours & 91.50 & 2.37 & 91.55 & 2.56 & 90.90 & 1.80 & 0.51 & 0.605 \\
\hline
\end{tabular}

Table (5): Respiratory rate among studied groups

\begin{tabular}{|c|c|c|c|c|c|c|c|c|c|}
\hline \multirow{2}{*}{\multicolumn{2}{|c|}{ RR }} & \multicolumn{2}{|c|}{ Granisetron } & \multicolumn{2}{|c|}{ Pethidine } & \multicolumn{2}{|c|}{ Tramadol } & \multirow[t]{2}{*}{$F$} & \multirow[t]{2}{*}{$P$} \\
\hline & & Mean & SD & Mean & SD & Mean & SD & & \\
\hline \multicolumn{2}{|l|}{ Basal } & 20.50 & 1.43 & 21.00 & 1.52 & 20.55 & 1.05 & 0.83 & 0.441 \\
\hline \multirow{6}{*}{ Intraoperative } & 15 minutes & 19.65 & 1.31 & 17.45 & 2.94 & 19.60 & 0.94 & 18.39 & $<0.001^{*}$ \\
\hline & 30 minutes & 19.75 & 1.21 & 16.80 & 2.91 & 19.55 & 0.76 & 15.49 & $<0.001^{*}$ \\
\hline & 45 minutes & 19.60 & 1.14 & 17.55 & 0.83 & 19.25 & 0.91 & 25.62 & $<0.001^{*}$ \\
\hline & 60 minutes & 19.85 & 1.14 & 17.50 & 0.69 & 19.10 & 0.85 & 34.69 & $<0.001^{*}$ \\
\hline & 75 minutes & 19.55 & 0.94 & 17.40 & 0.60 & 19.40 & 0.75 & 47.54 & $<0.001^{*}$ \\
\hline & Final & 19.70 & 1.08 & 17.50 & 0.76 & 19.25 & 0.91 & 31.46 & $<0.001^{*}$ \\
\hline \multirow{6}{*}{ Postoperative } & 0 minute & 19.55 & 0.76 & 17.70 & 0.66 & 19.40 & 0.94 & 33.48 & $<0.001^{*}$ \\
\hline & 30 minutes & 19.60 & 1.10 & 17.45 & 0.69 & 19.35 & 0.88 & 34.04 & $<0.001^{*}$ \\
\hline & 60 minutes & 19.35 & 0.88 & 17.50 & 0.69 & 19.40 & 0.94 & 33.13 & $<0.001^{*}$ \\
\hline & Two hours & 19.55 & 0.83 & 17.50 & 0.69 & 19.30 & 0.98 & 35.52 & $<0.001^{*}$ \\
\hline & Three hours & 19.50 & 1.05 & 17.75 & 0.91 & 19.55 & 0.94 & 22.31 & $<0.001^{*}$ \\
\hline & Four hours & 19.80 & 1.06 & 17.45 & 1.00 & 19.55 & 0.69 & 38.68 & $<0.001^{*}$ \\
\hline
\end{tabular}

Table (6): Oxygen saturation, and skin temperature among studied groups

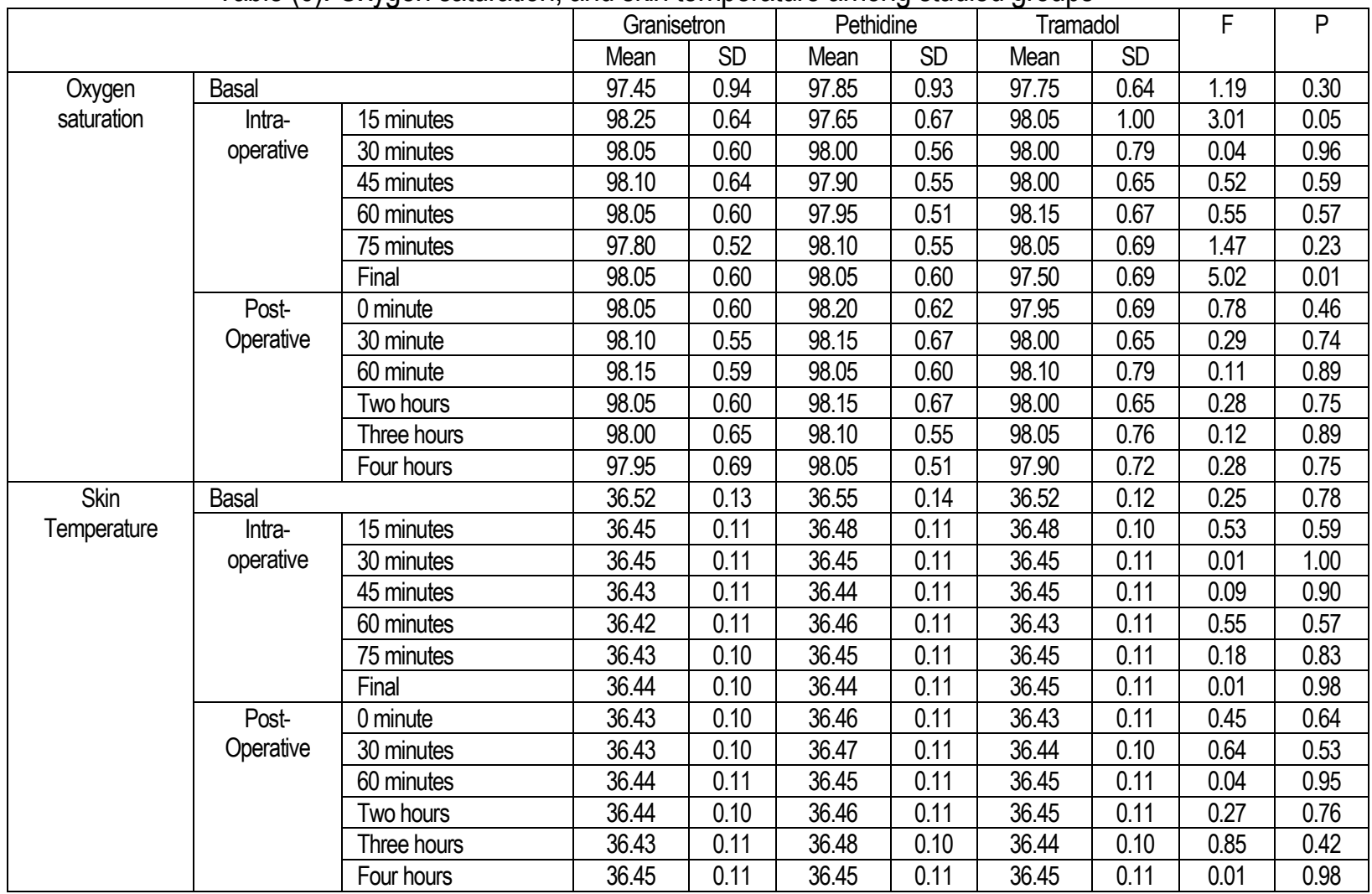


Table (7): Sedation score among studied groups

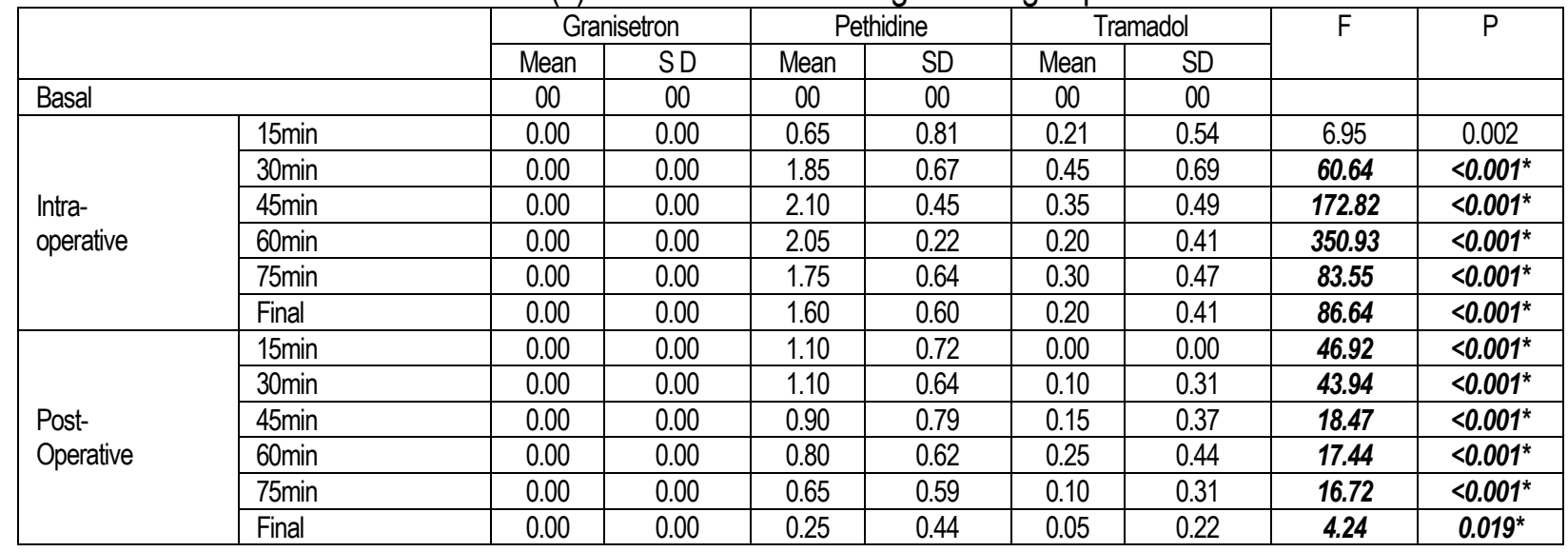

Table (8): Outcome among studied groups

\begin{tabular}{|c|c|c|c|c|c|c|c|c|c|}
\hline & & \multicolumn{2}{|c|}{ Granisetron } & \multicolumn{2}{|c|}{ Pethidine } & \multicolumn{2}{|c|}{ Tramadol } & \multirow[t]{2}{*}{ Test } & \multirow[t]{2}{*}{$P$} \\
\hline & & $\mathrm{N}$ & $\%$ & $\mathrm{n}$ & $\%$ & $\mathrm{n}$ & $\%$ & & \\
\hline Shivering & Yes & 3 & $15.0 \%$ & 5 & $25.0 \%$ & 3 & $15.0 \%$ & 0.89 & 0.64 \\
\hline \multirow{2}{*}{$\begin{array}{l}\text { Shivering } \\
\text { grade }\end{array}$} & Mild & 2 & $66.70 \%$ & 1 & $20.0 \%$ & 0 & $0.0 \%$ & \multirow[t]{2}{*}{3.60} & \multirow[t]{2}{*}{0.16} \\
\hline & Moderate & 1 & $33.30 \%$ & 4 & $80.0 \%$ & 3 & $100.0 \%$ & & \\
\hline \multirow{2}{*}{$\begin{array}{l}\text { Nausea/ } \\
\text { vomiting }\end{array}$} & Yes & 0 & $0.0 \%$ & 4 & $20.0 \%$ & 2 & $10.0 \%$ & \multirow[t]{2}{*}{4.44} & \multirow[t]{2}{*}{0.10} \\
\hline & No & 20 & $100.0 \%$ & 16 & $80.0 \%$ & 18 & $90.0 \%$ & & \\
\hline \multirow[t]{2}{*}{ Pruritus } & Yes & 0 & $0.0 \%$ & 6 & $30.0 \%$ & 0 & $0.0 \%$ & \multirow[t]{2}{*}{13.33} & \multirow[t]{2}{*}{$0.001^{*}$} \\
\hline & No & 20 & $100.0 \%$ & 14 & $70.0 \%$ & 20 & $100.0 \%$ & & \\
\hline
\end{tabular}

\section{DISCUSSION}

Results of the present work revealed that, granisetron seems to be the most suitable antishivering agent in the present study, as the incidence of shivering is equal to tramadol (15\%) and less than pethidine (25\%), about two thirds of shivering was mild, had no nausea and/or vomiting and no pruritus. Tramadol comes in the second position as it is devoid of pruritis with less nausea and/or vomiting. Pethidine was the last in list of studied drugs as it associated with significantly low respiratory rate, highest incidence of shivering $(80 \%$ of them were moderate), high incidence of nausea and/or vomiting and pruritus was only reported with this group. However, granisetron is devoid of sedative action, but had stable hemodynamics. Gangopadhyay et al.[15] reported an incidence rate of perioperative shivering of $20 \%$ in pethidine group and $40 \%$ in tramadol group. Talakoub et al.[16] used tramadol for prophylaxis against shivering after spinal anesthesia. They reported that incidence of shivering was only $3 \%$ with tramadol but they documented only Grade 3 or 4 shivering. Piper et al.[17], reported incidence of post-operative shivering was $16.6 \%$ in pethidine group, which is less than that presented in the present work. Arshad et al.[18] compared between tramadol and pethidine and reported that, no significant respiratory depression was noted in any of studied patients. Tramadol controlled shivering in $90 \%$ of patients and pethidine in $77.5 \%$ of patients with no significant difference $(p=0.13)$. They added that, two patients in pethidine group developed nausea, but this did not need any treatment. In addition, Dhimar et al. [19] found tramadol and pethidine to be equally effective as well. However, tramadol stopped shivering sooner than pethidine. They also revealed the shivering recurrence rate to be low in tramadol and more nausea vomiting in pethidine group. On the other side, Sharma et al.[20] found pethidine to be more effective than tramadol in prophylaxis of shivering at 10, 15, 20 and $30 \mathrm{~min}$ while there was no significant difference at 5 and 25 min after giving study drugs. Pethidine was associated with more sedation (as in the present work for this point) and tramadol caused significant nausea and vomiting. This could be attributed to different doses of used drugs between studies.

The anti-shivering effect of pethidine could be mediated by $k$ receptor ${ }^{[11]}$. The sites of action for pethidine include their actions on pre-optic neurons, neurons of anterior hypothalamus, dorsal raphe nucleus and also spinal cord[1]. 
On the other side, the anti-shivering action of tramadol could be mediated by inhibiting the reuptake of norepinephrine and serotonin. Thus, stimulating the descending inhibitory spinal pathways. It also modulates the action of nucleus magnus raphe[18].

In the present study, temperature was in normal range allover the study duration and there was no significant difference between studied groups. However, shivering was reported. These results are comparable to Crossley[21] who reported that, postoperative shivering could happen, even in patients without hypothermia.

This was explained in a study by Frank et al.[22] who stated that, that the core body temperature set point elevated after surgery. Theoretically, postoperative shivering can be considered as a heat-producing reaction to the postoperative increase in the core body temperature set point.

Talakoub et al.[16] also reported that, $77.8 \%$ of patients in tramadol group had nausea but only $30 \%$ need rescue antiemetic. However, Wrench et al.[23] did not document any adverse reaction after pethidine injection while Chu et al.[24] reported an incidence of $10 \%$.

Gangopadhyay et al.[15] reported that, pruritus was a significant adverse reaction with higher incidence in pethidine group.

In addition, Piper et al.[17], Talakoub et al.[16], Chu et al.[24] also reported an increased incidence of pruritus in pethidine group.

Shivering is associated with increased oxygen consumption to up to five folds, reduce arterial oxygen saturation and has been correlated with higher risk of myocardial ischemia; angina and wound pain[17].

In addition, shivering increases metabolic rate up to four folds as normal basal rate ${ }^{[13]}$. Postoperative shivering could be associated with delayed hospital discharge and is a common cause of discomfort in patients during recovery from anesthesia[25].

Different pharmacological agents like pethidine, fentanyl, morphine, ketamine, tramadol, granisetron, clonidine and dexmedetomidine have been tried to control postoperative shivering[26-28].
Comparable to results of the present work, it had been reported that, serotonin antagonists (e.g., granisetron) have been used for the prevention of postoperative shivering associated spinal anesthesia [13]. In addition, the stable hemodynamics after granisetron is comparable to Tsikouris et al.[29], who observed that granisetron infusion is associated with decreased heart rate changes and decreased systolic blood pressure fluctuations. Furthermore, Mowafi et al.[30] and Rashad and Farmawy ${ }^{[31]}$ found that granisetron had no effect on hemodynamic variables, and granisetron has no hypotensive effects.

The anti- shivering effect of Granisetron (serotonin receptor antagonist), which has role in neurotransmission and thermoregulation suggesting the serotonergic system could be involved in the control of post anesthetic shivering, also 5-hydroxy tryptamine receptor antagonist used as antiemetic's routinely.[29],

Kabade et al. [32] compared granisetron to pethidine in prophylaxis of shivering after spinal anesthesia and concluded that, prophylactic administration of granisetron $40 \mathrm{mcg} / \mathrm{kg}$ IV is equally effective as pethidine $0.4 \mathrm{mg} / \mathrm{kg}$ in prevention of perioperative shivering after spinal anesthesia, maintains core temperature and oxygen saturation levels above that of pethidine. In addition, granisetron also decreases the need of antiemetics.

In summary, results of the present work revealed the effectiveness of all studied drugs in prevention of perioperative shivering related to spinal anesthesia. In addition, granisetron seems to be the most reasonable drug in such situation. However, the small sample size is against the globalization of results.

\section{Financial and Conflict of interest disclosure}

Author declares that there was no conflict of interest.

\section{REFERENCES}

1. De Witte J, Sessler DI. Perioperative shivering. Anesthesiology 2002: 96: 467-84. [DOI:10.1097/ 00000542-200202000-00036]

2. Bhattacharya $P$, Bhattacharya L. Postanaesthetic shivering (PAS): A review. Indian J Anaesth. 2003; 47: 88- 93. 
3. Warttig S, Alderson P, Campbell G, Smith AF. Interventions for treating inadvertent postoperative hypothermia. Cochrane Database Syst Rev. 2014; CD009892. [DOI: 10.1002/ 14651858. CD009892. pub2].

4. Kinjo T, Tadokoro T, Tokushige A, Zamami T, Taira S, Ikehara Y, et al. Effects of Perioperative Administration of Acetaminophen on Postoperative Shivering: A Randomized, Triple-Blind, PlaceboControlled Trial. Anesth Analg. 2019 Jun 24. [Doi: 10.1213/ANE. 0000000000004306]. [Epub ahead of print]

5. Wason R, Jain N, Gupta P, Gogia AR. Randomized double-blind comparison of prophylactic ketamine, clonidine and tramadol for the control of shivering under neuraxial anesthesia. Indian J Anaesth. 2012; 56:370-5. [DOI: 10.4103/00195049.100821].

6. Eberhart LH, Döderlein F, Eisenhardt G, Kranke P, Sessler DI, Torossian A, Wulf H, Morin AM. Independent risk factors for postoperative shivering. Anesth Analg. 2005; 101:1849-1857. [DOI:10.1213/ 01.ANE.0000184128. 41795.FE].

7. Diaz M, Becker DE. Thermoregulation: Physiological and clinical considerations during sedation and general anesthesia. Anesth Prog 2010; 57:25-32. [DOI: 10.2344/ 0003-3006-57.1.25].

8. Liu ZX, Xu FY, Liang X, Zhou M, Wu L, Wu JR, Xia $\mathrm{JH}$, Zou Z. Efficacy of dexmedetomidine on postoperative shivering: a meta-analysis of clinical trials. Can J Anaesth. 2015; 62:816-829. [DOI: 10.1007/s12630-015-0368-1].

9. Wang W, Song X, Wang T, Zhang C, Sun L. 5-HT3 receptor antagonists for the prevention of perioperative shivering: a meta-analysis. J Clin Pharmacol. 2017; 57:428-439. [DOl:10.1002/jcph.829].

10. Park SM, Mangat HS, Berger K, Rosengart AJ. Efficacy spectrum of anti-shivering medications: meta-analysis of randomized controlled trials. Crit Care Med. 2012; 40: 3070-3082. [DOI:10.1097/CCM.0b013e31825b931e].

11. Buggy DJ, Crossley AW. Thermoregulation, mild peri-operative hypothermia and post-anaesthetic shivering. $\mathrm{Br} J$ Anaesth. 2000; 84: 615-28. [DOI: 10.1093/bja/ 84.5.615].

12. Kawakami H, Nakajima D, Mihara T, Sato H, Goto T. Effectiveness of Magnesium in Preventing Shivering in Surgical Patients: A Systematic Review and Meta-analysis. Anesth Analg. 2019; 129:689-700. [DOI: 10. 1213/ ANE. 0000000000004024].
13. Iqbal A, Ahmed A, Rudra A, Sengupta S, Das T, Roy D. Prophylactic Granisetron Vs Pethidine for the Prevention of Postoperative Shivering: A Randomized Control Trial. Indian J Anaesth. 2009; 53(3):330- 334. [PMID: 20640142].

14. Ozgencil E, Yalcin S, Tuna H, Yorukoglu D, Kecik Y. Perioperative administration of gabapentin $1,200 \mathrm{mg}$ day-1 and pregabalin $300 \mathrm{mg}$ day- 1 for pain following lumbar laminectomy and discectomy: a randomized, double-blinded, placebo-controlled study. Singapore Med J. 2011; 52:883-889. [PMID: 22159931].

15. Gangopadhyay S, Gupta K, Acharjee S, Nayak SK, Dawn S, Piplai G. Ketamine, Tramadol and Pethidine in Prophylaxis of Shivering During Spinal Anaesthesia. J Anaesth Clin Pharmacol. 2010; 26(1): 59-63

16. Talakoub R, Sk Noori Meshkathi. Tramadol versus meperidine in the treatment of shivering during spinal anesthesia in caesarean section. J Res Med Sci. 2006; 11: 151-56

17. Piper SN, Maleck WH, Boldt J, Suttner SW, Schmidt CC, Reich DG. A comparison of urapidil, clonidine, meperidine and placebo in preventing post-anesthetic shivering. Anesth Analg 2000; 90; 954-57. [DOI: 10.1097/00000539-20000400000033].

18. Arshad M, Ali L, Khalid A, Ahmad MN, Taqi A. A randomized controlled trial to compare the efficacy of pethidine and tramadol for postoperative shivering. Anaesth Pain \& Intensive Care 2017; 21(4):427-431

19. Dhimar AA, Patel GM, Swadia VN. Tramadol for Control of Shivering (Comparison with pethidine). Indian J Anaesth. 2007; 51(1):28-31.

20. Sharma M. Kharbuja K, Khadka B. Comparison of pethidine and tramadol for the control of shivering in patients undergoing elective surgery under spinal anesthesia. J Lumbini Med Coll. 2016; 4(2):64-7. [DOI: 10.22502/ jlmc. v4i2.92].

21. Crossley AW. Peri-operative shivering. Anesthesia 1992; 47:193-195. [DOI: 10.1111/j.1365-2044. 1992.tb 02114.x].

22. Frank SM, Kluger MJ, Kunkel SL. Elevated thermostatic setpoint in postoperative patients. Anesthesiology 2000; 93:1426-1431. [DOl: 10.1097/ 00000542-200012000-00014].

23. Wrench IJ, Carill JE, Ward JE, Crossley AW. Comparison between alfentanyl, pethidine and placebo in the treatment of post anesthetic shivering. Br J Anaesth. 1997; 79: 541-42. [DOI:10. 1093/ bja/79.4.541]. 
24. Tsai YC, Chu KC. A comparison of tramadol, amitriptyline and meperidine for post-epidural anesthetic shivering in parturient. Anesth Analg. 2001; 93: 1288-92. [DOl:10.1097/00000539200111000-00052].

25. Daniel I. Sessler. Perioperative Thermoregulation. In: Silverstein J, Rooke A, Reves, JG, McLeskey $\mathrm{CH}$, editors. Geriatric anesthesiology. $2^{\text {nd }}$ ed. New York (NY): Springer; 2007; p107-122.

26. Elvan EG, Uzan S, Karabulat E, Coskun F, Aypar

$\mathrm{U}$. Dexmedetomidine and postoperative shivering in patients undergoing elective abdominal hysterectomy. Eur J Anaesthesiol. 2008; 25(5): 357-64. [DOI: 10.1017/ S0265021507003110].

27. Seifi A, Avestimehr S, Mowla A, Kamalipour H. A comparative study of the effect of tramadol and pethidine on postoperative shivering. The Internet J Anesthesiol. 2008; 16(2) [DOI: 10.5580/1817].

28. Norouzi M, Doroodian MR, Salajegheh S. Optimum dose of ketamine for prevention of postanesthetic shivering; a randomized doubleblind placebo controlled clinical trial. Acta Anaesthesiol Belg. 2011; 62(1):33-6. [PMID: 21612143].
29. Tsikouris JP, Kluger J, Chow MS, White CM. Usefulness of intravenous granisetron for prevention of neurally mediated hypotension upon head upright tilt testing. Am J Cardiol. 2000; 85:1262-1264. [DOI:10.1016/s0002-9149 (00) 00743-8].

30. Mowafi HA, Arab SA, Ismail SA, Al-Ghamdi A. The effects of intravenous granisetron on the sensory and motor blockade produced by intrathecal bupivacaine. Anesth Analg. 2008; 106:1322-1325. [DOI: 10.1213/ane. 0b013e318165e012].

31. Rashad MM, Farmawy MS. Effects of intravenous ondansetron and granisetron on hemodynamic changes and motor and sensory blockade induced by spinal anesthesia in parturients undergoing cesarean section. Egypt J Anaesth. 2013; 29:369374. [DOI: 10.1016/j.egja.2013.04.004].

32. Kabade SD, Venkatesh Y, Karthik S, Kumar V. Comparative study of granisetron versus pethidine for the prevention of perioperative shivering under spinal Anesthesia. Karnataka Anaesth J. 2016; 2:14-8. [DOI: 10.4103/ 2394-6954.190769]. 